\title{
Design and optimization of porous ceramic supports for asymmetric ceria-based oxygen transport membranes
}

Kaiser, Andreas; Foghmoes, Søren Preben Vagn; Peanac, G.; Malzbender, J.; Chatzichristodoulou, Christodoulos; Glasscock, Julie; Kothanda Ramachandran, Dhavanesan; Ni, De Wei; Esposito, Vincenzo; Søgaard, Martin

Total number of authors:

11

Published in:

Journal of Membrane Science

Link to article, DOI:

10.1016/j.memsci.2016.04.016

Publication date:

2016

Document Version

Peer reviewed version

Link back to DTU Orbit

Citation (APA):

Kaiser, A., Foghmoes, S. P. V., Peanac, G., Malzbender, J., Chatzichristodoulou, C., Glasscock, J., Kothanda Ramachandran, D., Ni, D. W., Esposito, V., Søgaard, M., \& Hendriksen, P. V. (2016). Design and optimization of porous ceramic supports for asymmetric ceria-based oxygen transport membranes. Journal of Membrane Science, 513, 85-94. https://doi.org/10.1016/j.memsci.2016.04.016

\section{General rights}

Copyright and moral rights for the publications made accessible in the public portal are retained by the authors and/or other copyright owners and it is a condition of accessing publications that users recognise and abide by the legal requirements associated with these rights.

- Users may download and print one copy of any publication from the public portal for the purpose of private study or research.

- You may not further distribute the material or use it for any profit-making activity or commercial gain

- You may freely distribute the URL identifying the publication in the public portal 


\section{Design and optimization of porous ceramic supports for asymmetric ceria-based oxygen transport membranes}

${ }^{1}$ A. Kaiser*, ${ }^{1}$ S. P. Foghmoes, ${ }^{2}$ G. Pećanac, ${ }^{2}$ J. Malzbender, ${ }^{1}$ C. Chatzichristodoulou, ${ }^{1}$ J.A. Glasscock, ${ }^{1}$ D. Ramachandran, ${ }^{1}$ De Wei Ni, ${ }^{1}$ V. Esposito, ${ }^{1}$ M. Søgaard and ${ }^{1}$ P.V. Hendriksen ${ }^{1}$ Department of Energy Conversion and Storage, Technical University of Denmark, Frederiksborgvej 399, DK-4000 Roskilde, Denmark

${ }^{2}$ Forschungszentrum Jülich GmbH, Institute of Energy and Climate Research, IEK-2, D-52425

Jülich

*Corresponding author, Tel.: +45 4677 5889; fax: +45 4677 5858. E-mail address: akai@risoe.dtu.dk

\section{Abstract}

The microstructure, mechanical properties and gas permeability of porous supports of $\mathrm{Ce}_{0.9} \mathrm{Gd}_{0.1} \mathrm{O}_{1.95-\delta}(\mathrm{CGO})$ were investigated as a function of sintering temperature and volume fraction of pore former for use in planar asymmetric oxygen transport membranes (OTMs). With increasing the pore former content from 11 vol.- $\%$ to 16 vol.- $\%$, the gas permeabilities increased by a factor of 5 when support tapes were sintered to comparable densities. The improved permeabilities were due to a more favourable microstructure with larger interconnected pores at a porosity of $45 \%$ and a fracture strength of $47 \pm 2 \mathrm{MPa}(\mathrm{m}=7)$. The achieved gas permeability of $2.25 \times 10^{-15} \mathrm{~m}^{2}$ for a $0.4 \mathrm{~mm}$ thick support will not limit the gas transport for oxygen production but in partial oxidation of methane to syngas at higher oxygen fluxes. For integration 
of the CGO support layer into a flat, asymmetric CGO membrane, the sintering activity of the CGO membrane was reduced by $\mathrm{Fe}_{2} \mathrm{O}_{3}$ addition (replacing $\mathrm{Co}_{3} \mathrm{O}_{4}$ as sintering additive).

\section{Keywords}

Oxygen transport membrane; ceramic support; mechanical properties; gas permeability; co-firing

\section{Introduction}

Oxygen transport membranes (OTMs) based on mixed ionic electronic conducting oxides (MIEC) are ceramic devices which can be used to extract pure oxygen from air and supply the oxygen into combustion processes or chemical reactions to improve process efficiencies [1], [2], [3]. Recently, thin film oxygen transport membranes based on chemically very stable materials, such as gadolinium doped ceria $\left(\mathrm{Ce}_{0.1} \mathrm{Gd}_{0.9} \mathrm{O}_{1.95-\delta}, \mathrm{CGO}\right)$, have been shown to be able to sustain

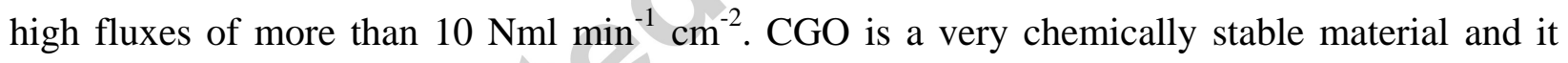
should be possible to use the material in asymmetric OTMs for the direct integration into membrane reactors operating under harsh conditions (temperatures above $750{ }^{\circ} \mathrm{C}$ and reducing and aggressive gases), such as for syngas production [4], [5], [6] and oxidative coupling of methane (OCM) [7].

One of the drawbacks in utilizing single phase, mixed conducting CGO as a membrane material for OTMs is the limiting electronic conductivity at temperatures below $750^{\circ} \mathrm{C}$ and at relatively high oxygen partial pressures [8], [9]. For this reason, membranes based on CGO can only reach the flux targets required for economical competiveness if a couple of requirements are fulfilled: (1) a membrane layer thickness well below $50 \mu \mathrm{m}$, which can be realized by the deposition of 
the dense membrane layer on a porous, mechanically strong supporting ceramic structure, resulting in a so called asymmetric thin film membrane, (2) very reducing conditions $\left(\mathrm{pO}_{2}<10^{-12}\right.$ atm) on one side of the membrane ("fuel side") to enhance the electronic conductivity of the material (by reduction of $\mathrm{Ce}^{4+}$ to $\mathrm{Ce}^{3+}$ ions in the fluorite structure) and (3) a large applied driving force during membrane operation (large $\Delta \mathrm{pO}_{2}$ between the fuel and air side). Asymmetric CGO membranes were therefore first tested for applications that fulfil these requirements. In laboratory scale tests, a high oxygen flux of $16 \mathrm{Nml} \mathrm{cm}^{-2} \min ^{-1}$ at $900{ }^{\circ} \mathrm{C}$ was obtained for a $30 \mu \mathrm{m}$ thick CGO membrane on a porous Ni-YSZ support, which was operated under conditions relevant for syngas production [4].[5]. Additional requirements for the asymmetric membrane architecture are determined by the properties and fabrication methods of the catalytic layers and the porous ceramic support. For example, in the case of the planar, asymmetric CGO membranes investigated for syngas production [4], the membrane consisted of a tape casted, thick porous Ni-YSZ support and an active Ni-YSZ catalyst layer, which were laminated together with a thin CGO membrane layer and subsequently co-sintered at a relatively high temperature of about $1300^{\circ} \mathrm{C}$ (see Figure 1a). 


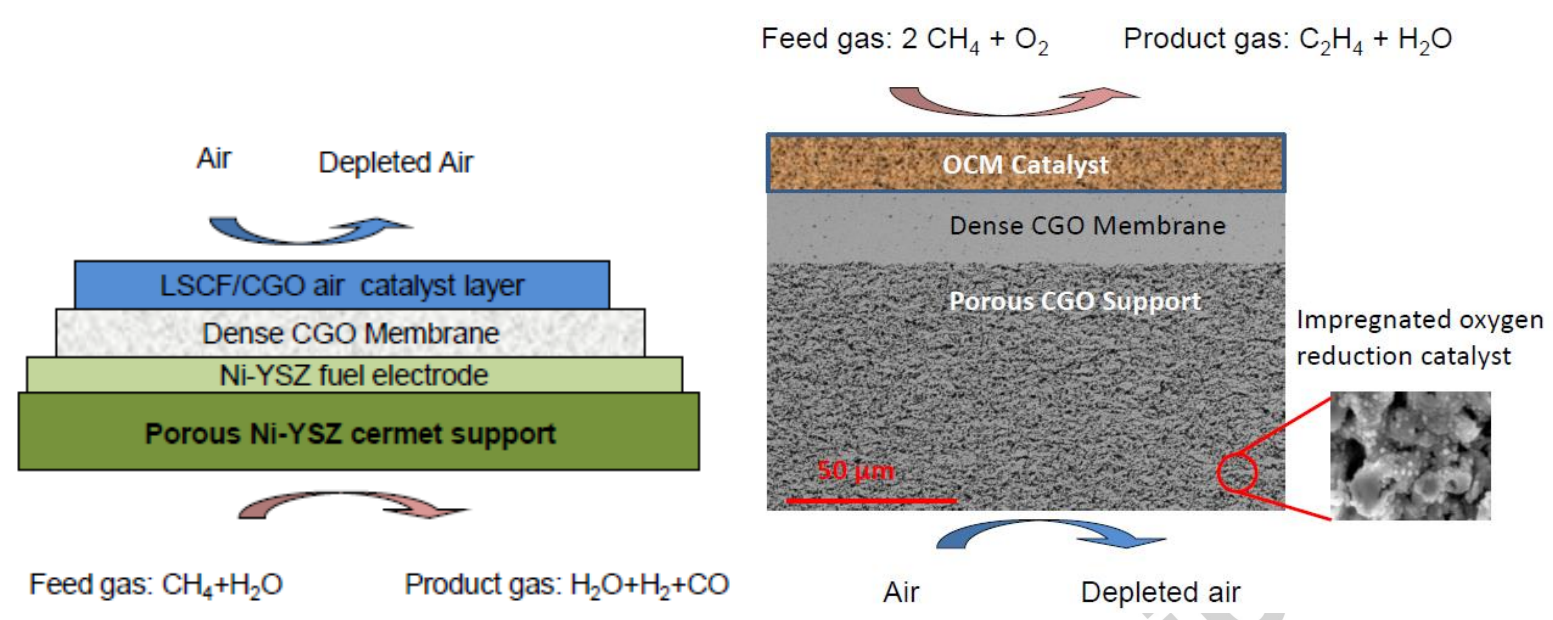

Figure 1: Schematic of different asymmetric CGO membrane architectures tested for OTM applications: a) Ni-YSZ supported membrane for syngas production on the permeate (fuel) side [4] and b) porous ceramic supported membrane which allows catalyst flexibility by infiltration after firing [10]. On the air side of the membranes an additional oxygen reduction catalyst was applied for both asymmetric membrane types after co-firing of the multilayer (in case b, the air catalyst was $\mathrm{La}_{0.6} \mathrm{Sr}_{0.4} \mathrm{CoO}_{3-\delta}$ as described in [10]).

A porosity of more than $35 \%$, required for gas transport through the support structure, was introduced into the $0.3 \mathrm{~mm}$ thick NiO-YSZ support by the volume change resulting from reducing the $\mathrm{NiO}$ to metallic nickel [11], [12],[13], [14]. If such asymmetric CGO membranes should be used for further applications in membrane reactors, for example in OCM [7], the nickel catalyst in the Ni-YSZ supports (used for syngas application) needs to be replaced by a more suitable catalyst (e.g. $\mathrm{Mn} / \mathrm{Na}_{2} \mathrm{WO}_{4} / \mathrm{SiO}_{2}$ ). Hence, for a flexible design the Ni-YSZ cermet support should be replaced entirely by a catalyst free (nickel free) porous ceramic material that could be used as a generic support for various catalysts/chemical reactions. A specific catalyst system as required for a specific chemical reaction can then be introduced into the sintered 
ceramic support structure by infiltration techniques [10]. Several support materials, such as 3YSZ, MgO and CGO were considered. Regardless of the selected material, the design of a new ceramic support requires a microstructure with

(a) sufficient gas permeation and mechanical strength (both influenced by the porosity),

(b) a good thermomechanical and chemical match with the thin film CGO membrane layer, e.g. avoiding chemical reactions between the layers and minimization of thermal stresses.

(c) tailored sintering behaviour (shrinkage) of the individual layers for co-sintering in an asymmetric structure.

We shall discuss these requirements in more detail below. With respect to requirement (a), a high gas permeability of a porous ceramic support structure should be achieved by creating sufficient open porosity in the range of 30 to $40 \%$ (after firing). Different approaches can be adopted to produce a support structure with sufficient porosity. One of the most suitable approaches is the use of a sacrificial pore former, especially if a co-firing of asymmetric porous-dense multi-layers is considered. For this case the pore former, e.g. graphite, is added to the tape casting formulation and is subsequently removed during de-binding to produce the required pores. Corbin et al [15] showed that graphite is an efficient pore forming agent that can be added in variable amounts to create porosities between 20 and $80 \%$ in tape-casted layers (of yttrium stabilized zirconia (YSZ)) without a significant change in the total shrinkage during sintering. To ensure good gas permeability through a porous membrane support and sufficient mechanical strength, the open porosity should usually be in the range of 35 to $50 \%$ depending on the thickness and microstructure of the support structure (at thicknesses of 0.5 to $1.5 \mathrm{~mm}$ ). The oxygen flux through an asymmetric membrane can even be limited by gas diffusion in a fine 
porous support structure with a thickness below $0.5 \mathrm{~mm}$ if the pores are narrow and if the pores are then partly infiltrated with catalyst material [16].

It was reported that an open percolating porous network can be formed in a ceramic body if inclusions (e.g. pore former with similar sized particles as the ceramic) exceed a volume fraction of $16 \%$ [17]. Alternatively, porosity may be introduced in the support structure by inhibiting the sintering activity of the ceramic by using a relatively coarse-grained powder (with particle size in the micron range). However, this can introduce a differential sintering shrinkage between the (coarse-grained) porous support and the fine-grained membrane layer which will result in stresses that cause defects in the bi-layer structure during the subsequent co-firing [18]. It is also a requirement that the support structure has sufficient porosity to ensure the infiltration of catalyst material into the region close to the support/membrane interface.

For requirement (b), a good thermal and chemical expansion match and full material compatibility (avoiding reactions between support and membrane layer) can be ensured by using a membrane architecture based on the same material (CGO) in both layers. Such an asymmetric membrane of a CGO membrane on a porous CGO support was therefore chosen as a starting point for a proof of concept demonstration, as visualized schematically in Figure 1b.

Furthermore, CGO is known to be a good ionic conducting (or under reducing conditions a mixed ionic-electronic conducting) electro catalyst that can extend the reaction zone (3 phase boundary) for oxygen removal into the catalytic layer [19] by increasing the "active" interface between the membrane layer and the active catalytic layer (here porous CGO support with respective catalysts). Finally, for the implementation of a porous CGO support in such an asymmetric CGO bi-layer, one of the most critical steps is the identification of a suitable co- 
firing procedure. In this step the membrane layer should be completely densified, simultaneously the porous support layer should sinter to a degree that sufficient mechanical strength is achieved (with open porosity between 30 and $45 \%$ open porosity, whereas at the same time thermally induced stresses between the two layers due to mismatch in differential shrinkage should be minimized. Based on previous studies on asymmetric porous/dense CGO bilayer structures, it is known that such structures can be produced by a co-firing process at relatively low temperatures $\left(\sim 1050{ }^{\circ} \mathrm{C}\right)$ if sintering additives, such as $\mathrm{Co}_{3} \mathrm{O}_{4}$ are used [20],[21] . Furthermore, theoretical sintering models have been developed that describe and confirm the distortion (camber) and shrinkage kinetics for such porous/dense CGO bi-layers [18], [22].

In this work, we describe the implementation and optimization of porous ceramic CGO support structures, prepared by tape casting, lamination and co-firing in an asymmetric CGO bilayer membrane, as shown schematically in Figure 1b. Performances (oxygen permeation fluxes) of such asymmetric CGO membranes, using these porous/dense CGO base structures, were already reported before [6] and are therefore not further discussed in this study.

Considering our experiences with the challenges of co-firing defect-free, flat and planar asymmetric porous/dense CGO structures [18], [20], [23], we start with a brief description of optical dilatometry studies on the different CGO layers with $\mathrm{Fe}_{2} \mathrm{O}_{3}$ and $\mathrm{Co}_{3} \mathrm{O}_{4}$ as sintering additives for isothermal co-sintering at low temperature (chapter 3.1). The dilatometer measurements of shrinkage and densification (rates) of different layers give us a guide to predict stresses and distortion (camber) for different combination of layers and sintering temperatures. Then, in the main part of this work we focus on the investigation and further optimization of the microstructure, mechanical properties and gas permeability of two different porous ceramic CGO 
support compositions as a function of the amount of pore former in the tape casting formulation and the (isothermal) sintering temperature (chapters 3.2 to 3.4).

\section{Experimental}

\subsection{Raw Materials}

Ultra low surface area (ULSA) $\mathrm{Ce}_{0.9} \mathrm{Gd}_{0.1} \mathrm{O}_{1.95-\delta}$ (CGO10 from Rhodia S.A.,La Rochelle Cedex, France, specific surface area of $6.6 \mathrm{~m}^{2} / \mathrm{g}$ ) was used for the preparation of the ceramic tapes. The as-received CGO powder was used for the preparation of thin membrane tapes, whereas the same CGO powder was pre-calcinated at $1100{ }^{\circ} \mathrm{C}$ for $2 \mathrm{~h}$ (resulting in slightly reduced BET surface area of $5.5 \mathrm{~m}^{2} / \mathrm{g}$ ) for use in the porous support tapes. A graphite powder, V-UF1 99.9\% purity from Graphit Kropfmühl (Germany), was used as pore former for the support tapes.

$2 \mathrm{~mol} \%$ of cobalt was used as a sintering aid for both the support and membrane tapes and added in the form of cobalt(II,III) oxide (Alfa Aesar, 99.7\%). Alternatively, 2 mol\% of iron, added as iron(III) oxide (Alfa Aesar, $99.9 \%$ ), was used as a sintering aid in the thin membrane tape to adjust differences in shrinkage rates with the support layer, reducing bi-layer warping at higher sintering temperatures (see section 3.4).

\subsection{Preparation of membrane support}

Two compositions of CGO supports were tape cast by choosing different concentration of pore former (11 vol.-\% and 16.5 vol.-\%). The amount of ceramic (CGO), pore former (graphite), binder and dispersant of the two dried CGO tapes is shown in Table 1. 
Table 1: Composition of green tapes for preparation of porous CGO supports. Low graphite (LG) tapes contain 11 vol.-\% graphite, high graphite (HG) tapes contain 16.5 vol.-\% of graphite.

\begin{tabular}{ccccc}
\hline & $\begin{array}{c}\text { Ceramics } \\
\text { a Vol.- } \%\end{array}$ & Graphite & Dispersant & Binder system \\
& Vol.- \% & Vol.- \% & Vol.- \% \\
\hline $\begin{array}{c}{ }^{\mathrm{b}} \text { Membrane } \\
\text { layer }\end{array}$ & 40.0 & 0.0 & 8.0 & 52.0 \\
${ }^{\mathrm{c}}$ LG support & 31.0 & 11.0 & 4.5 & 53.5 \\
${ }^{\mathrm{c}} \mathrm{HG}$ support & 25.0 & 16.5 & 3.5 & 55.0 \\
\hline
\end{tabular}

${ }^{\text {a }}$ Compositions were calculated in vol.-\% based on the dried green tapes

${ }^{\mathrm{b}}$ Two membrane layers were produced, one containing 2 mol- $\% \mathrm{Co}_{3} \mathrm{O}_{4}$ (Co-CGO membrane) and one containing 2 mol- $\% \mathrm{Fe}_{2} \mathrm{O}_{3}$ (Fe-CGO membrane) as sintering additives.

${ }^{\mathrm{c}}$ The LG support and HG support were produced with $\mathrm{Co}_{3} \mathrm{O}_{4}$ as sintering additive.

Tape casting slurries were prepared by dispersing the CGO powders and the sintering aid (cobalt nitrate) in a methylethylketone and ethanol solvent mixture (MEKET) with polyvinylpyrrolidone (PVP) as a dispersant, similar to a procedure described previously [6], [24]. These mixtures were typically ball milled for $72 \mathrm{~h}$ in PE bottles using zirconia balls with a diameter of $5 \mathrm{~mm}$. The particle size (d50) after milling was typically around $0.4 \mu \mathrm{m}$ in the slurry for the support tape with both particle size distributions (PSD's) exhibiting a bimodal distribution. A Polyvinylbutyral (PVB) binder is finally added together with a plasticiser to the slurries and the slurries were then slowly rotated for another $24 \mathrm{~h}$ to allow for proper homogenization. Sequential 
addition of graphite powder to the slurry in three equal portions within 2 hours were required for the preparation of the thick, porous support in order to obtain a proper mixing.

The slurries were finally filtered and de-aired before tape casting onto a polymer film. The thick support tapes were cast at $1.2 \mathrm{~mm}$ doctor blade height, corresponding to sintered thicknesses of about $300 \mu \mathrm{m}$ for the support (with actual final thicknesses depending on the sintering temperature). The samples were then heat treated at low temperature $\left(<800{ }^{\circ} \mathrm{C}\right)$ with a heating rate of $0.5 \mathrm{~K} / \mathrm{min}$ to remove the organics and pore-former, and subsequently sintered on a porous sintering substrate in air for $4 \mathrm{~h}$ at temperatures of 1050,1150 or $1250{ }^{\circ} \mathrm{C}$.

Throughout this work, the supports will be referred to with a combination of a two letter code that is related to the graphite content and a four digit number that is related to the sintering temperature. For example, LG1050 refers to a support with a low graphite (LG) of 11 vol.-\% content sintered at $1050{ }^{\circ} \mathrm{C}$ and HG1250 to a support with a high graphite (HG) content of 16.5 vol.- $\%$ sintered at $1250{ }^{\circ} \mathrm{C}$.

\subsection{Preparation of CGO membrane layers and asymmetric CGO bi-layers}

A thin, tape cast CGO membrane layer was prepared using the same slurry composition and procedures as for the porous support layer (see section 2.2) by using the uncalcined, as-recieved CGO powder and no addition of graphite powder. The tape cast layers of the thin film CGO membrane and the porous CGO support were combined by lamination (i.e. application of heat and pressure on to the tubes between two rolls). Circular disc membranes $(\varnothing=34 \mathrm{~mm})$ were stamped out from the green membrane tapes before sintering. In a binder removal step the 
organics were removed by a very slow de-binding profile to avoid damage of the structure (heating rate of $0.25 \mathrm{~K} / \mathrm{min}$, isothermal holding at 200,400 and $600{ }^{\circ} \mathrm{C}$ for $2 \mathrm{hrs}$ ). Subsequently, the structures were sintered in air at final temperatures between 1050 and $1250{ }^{\circ} \mathrm{C}$ (results are only shown for temperatures up to $1150{ }^{\circ} \mathrm{C}$ ). The sintered membrane structures were laser-cut to the final dimensions (diameter of $15 \mathrm{~mm}$ )

After sintering, all samples were visually inspected for defects such as cracks and deformation. Additionally, in an ethanol leak test, a single drop of ethanol was applied to find small cracks in the membrane bi-layers by looking for a possible staining on the support side due to leakage of ethanol through the thin membrane layer. Light microscopy was used if the results from the leak test were not clear.

\subsection{Characterization of CGO supports}

The specific surface area was measured by gas adsorption measurements, using the BET method with a Quantachrome Autosorb 1 after degassing for $300{ }^{\circ} \mathrm{C}$ for $3 \mathrm{hrs}$ and surface absorption with krypton gas.

Porosimetry measurements were conducted using an automatic Hg-porosimeter (AutoPore IV 9510, Micromeritics, Norcross/GA, USA). All samples were measured in a penetrometer with 5 $\mathrm{cm}^{3}$ bulb volume and a usable $\mathrm{Hg}$ volume in the penetrometer stem of $0.392 \mathrm{~cm}^{3}$, allowing for a maximum measureable pore volume of $0.366 \mathrm{~cm}^{3}$. Scans were run intrusion-controlled, meaning that the system pressure was only increased after the $\mathrm{Hg}$ intrusion fell below $0.01 \mu \mathrm{l} /(\mathrm{g} \cdot \mathrm{s})$. All scans were run between $5 \mathrm{~Pa}$ and $420 \mathrm{MPa}$ translating into a measurement range between 240 $\mu \mathrm{m}$ and $0.003 \mu \mathrm{m}$ pore diameter. The measurement resolution depends on the actual pressure $( \pm$ $0.1 \mu \mathrm{m}$ or $\pm 2 \mathrm{~nm}$ for the pore size ranges $12-0.04 \mu \mathrm{m}$, and $0.04 \mu \mathrm{m}-3 \mathrm{~nm}$, respectively). 
SEM was conducted with an Hitachi TM1000 microscope to investigate the microstructure of the porous CGO supports and the asymmetric CGO bi-layers. The porous samples were mounted in epoxy, polished with a 1/4 micron diamond suspension, and coated with carbon before use in the SEM.

A non-contact optical dilatometry (TOMMI, Fraunhofer Institut, [23]. [25]) was used to study the shape evolution of membrane bi-layers $(2 \mathrm{~cm} \times 2 \mathrm{~cm}$ pieces $)$ under binder burn out and sintering. Images were captured every 10 minutes for several temperature profiles with a maximum temperature in the range from $1050{ }^{\circ} \mathrm{C}$ to $1250{ }^{\circ} \mathrm{C}$. Samples were sintered both with and without a load (cover plate).

Laser profilometry measurements were conducted on the sintered porous supports to confirm that the samples used for mechanical testing had sufficient flatness. A Cyberscan Vantage (Cyberscan Technologies) with a $670 \mathrm{~nm}$ wavelength laser was used. For scans over the entire samples (diameter of $23 \mathrm{~mm}$, thickness about $0.5 \mathrm{~mm}$ ) a step size of $25 \mu \mathrm{m}$ and a DRS8000 sensor was used, whereas for detailed scans of $0.1 \mathrm{~mm} \times 0.1 \mathrm{~mm}$ a step size of $1 \mu \mathrm{m}$ a Keyence LT-9010 M sensor was used. All measurements were based on a 4-point average for every measurement point, and any missing data points were generated from an average of the surrounding points. Laser profilometry confirmed that the supports had warping below $\pm 50 \mu \mathrm{m}$ over the entire sample $(\mathrm{d}=23 \mathrm{~mm})$ and were suitable for mechanical testing.

Mechanical characterization of the porous CGO supports was conducted by biaxial ring-on-ring bending tests. The tests [26] were carried out, following the ASTM standard (C1499-05). The 
circular disk specimens $\left(r_{3} \sim 13 \mathrm{~mm}\right)$ were supported by an outer ring $\left(r_{2} \sim 7.5 \mathrm{~mm}\right)$ and loaded with a smaller coaxial inner ring $\left(r_{1} \sim 3.95 \mathrm{~mm}\right)$ with a loading rate of $100 \mathrm{~N} / \mathrm{min}$ at room temperature in air. The samples had an overall thickness of $\sim 0.3 \mathrm{~mm}$. The data were evaluated using the equation for linear bending theory [27]. Hence, the equibiaxial flexure stress was derived from:

$\sigma_{b}=\frac{3 \cdot F \cdot(1+v)}{2 \cdot \pi \cdot t^{2}} \cdot\left[\ln \left(\frac{r_{2}}{r_{1}}\right)+\left(\frac{1-v}{1+v}\right) \cdot\left(\frac{r_{2}^{2}-r_{1}^{2}}{2 \cdot r_{3}^{2}}\right)\right]$

where $F$ is the applied force, $t$ is the specimen thickness, and $v$ is the Poisson ratio. The Young's modulus was determined from the load-displacement data using [27]:

$E=\frac{3 \cdot F \cdot\left(1-v^{2}\right) \cdot r_{1}^{2}}{2 \cdot \pi \cdot d \cdot t^{3}} \cdot\left[\left(\frac{r_{2}}{r_{1}}\right)^{2}-1-\ln \left(\frac{r_{2}}{r_{1}}\right)+\frac{1}{2} \cdot\left(\frac{1-v}{1+v}\right) \cdot\left(\frac{r_{2}^{2}-r_{1}^{2}}{r_{3}^{2}}\right) \cdot\left(\frac{r_{2}^{2}}{r_{1}^{2}}\right)\right]$

where $d$ is the vertical deflection of the specimen. According to Hooke's law, the critical rupture strain is defined as the ratio of characteristic strength and Young's modulus of the material.

The fracture stress and rupture strain data were used to determine the characteristic strength $\sigma_{f}$, characteristic rupture strain (both corresponding to a failure probability of $63.2 \%$ ), and the respective Weibull moduli $m$ using the linear regression analysis according to ASTM C1239-07, based on the relationship for the failure probability $P_{f}$ :

$P_{f}=1-\exp \left[-\left(\frac{\sigma}{\sigma_{f}}\right)^{m}\right]$ 
In the case of the characteristic rupture strains, the stress values in equation (3) have to be replaced by strains. Moreover, equation (3) can be used to predict the fracture stress for any technologically acceptable failure probability.

The tests were carried out with universal testing machines (Instron 1362 series). The central displacement of the specimen was detected with a sensor in contact with the lower surface of the sample. The actual displacement value was measured with a ceramic extension rod attached to a linear variable differential transformer (Sangamo, LVDT, range $\pm 1 \mathrm{~mm}$, precision $1.25 \mu \mathrm{m}$ ). The load was determined with a $1.5 \mathrm{kN}$ load cell (Interface $1210 \mathrm{BLR}$ ).

Gas permeation measurements were carried out using an in house built system. The setup consisted of a gas supply unit, a testing chamber and a unit for measuring the flow of the gas that permeates through the sample. A typical specimen is a planar support structure with an area of approximately 0.45 to $1 \mathrm{~cm}^{2}$. The thickness of the different porous CGO support samples varied from 0.35 to $0.45 \mathrm{~mm}$. A pressure difference across the sample was created using an electropneumatic pressure controller (Tescom, ER3000, USA). The flow of permeated gas was measured using a flow meter (Electronic flowmeter 5314, Agilent, USA). The measurements were made with a pressure difference ranging from 50 to $400 \mathrm{kPa}$, at room temperature and with nitrogen as the permeate gas.

The CGO supports were glued at one end to steel fixtures and to a polymer composite enclosure at the other end. Then gas permeation measurements were carried out in order to quantify the gas permeability using the Darcy equation:

$j=\frac{\kappa}{\mu} \nabla P$ 
where, $j$ is the flux $\left(\mathrm{m}^{3} \mathrm{~m}^{-2} \mathrm{~s}^{-1}\right), \kappa$ is the permeability $\left(\mathrm{m}^{2}\right), \mu$ is the viscosity of the gas $(\mathrm{Pa} \mathrm{s})$, and $\nabla P$ is the pressure gradient $\left(\mathrm{Pa} \mathrm{m}^{-1}\right)$.

\section{Results and Discussion}

\subsection{Isothermal sintering of CGO supports in asymmetric CGO bi-layer membranes}

Considering the importance of the co-firing process of asymmetric porous/dense ceramic bilayers, first asymmetric CGO bi-layers with different combinations of support and membrane layers were produced by lamination. These bi-layers were then co-sintered at a defined isothermal sintering cycle at a final temperature of $1050^{\circ} \mathrm{C}$. Previous work described the cofiring as a major challenge in the preparation of defect free asymmetric porous/dense CGO bilayers [6], [18]. The experiments demonstrated that defect free bi-layers could be produced by combination of individual layers of porous CGO supports (high graphite supports (HG-CGO) and low graphite (LG-CGO)) and membrane layers (Co-CGO and Fe-CGO) at an isothermal sintering temperature of $1050{ }^{\circ} \mathrm{C}$ and an holding time of $4 \mathrm{hrs}$. A typical structure of a bi-layer (HG-CGO support and Co-CGO membrane) is shown as a part of Figure 1b. Additionally, optical dilatometry was used to measure shrinkage strains and to be able to predict sintering stresses and camber development in the different bi-layers during co-sintering [22]. Figure 2 shows the dependence of shrinkage and shrinkage rate on the temperature of the two types of CGO supports in comparison to the two different CGO membrane layers which contain $\mathrm{Co}_{3} \mathrm{O}_{4}$ or $\mathrm{Fe}_{2} \mathrm{O}_{3}$ as sintering additives (Co-CGO and $\mathrm{Fe}-\mathrm{CGO}$ ). 

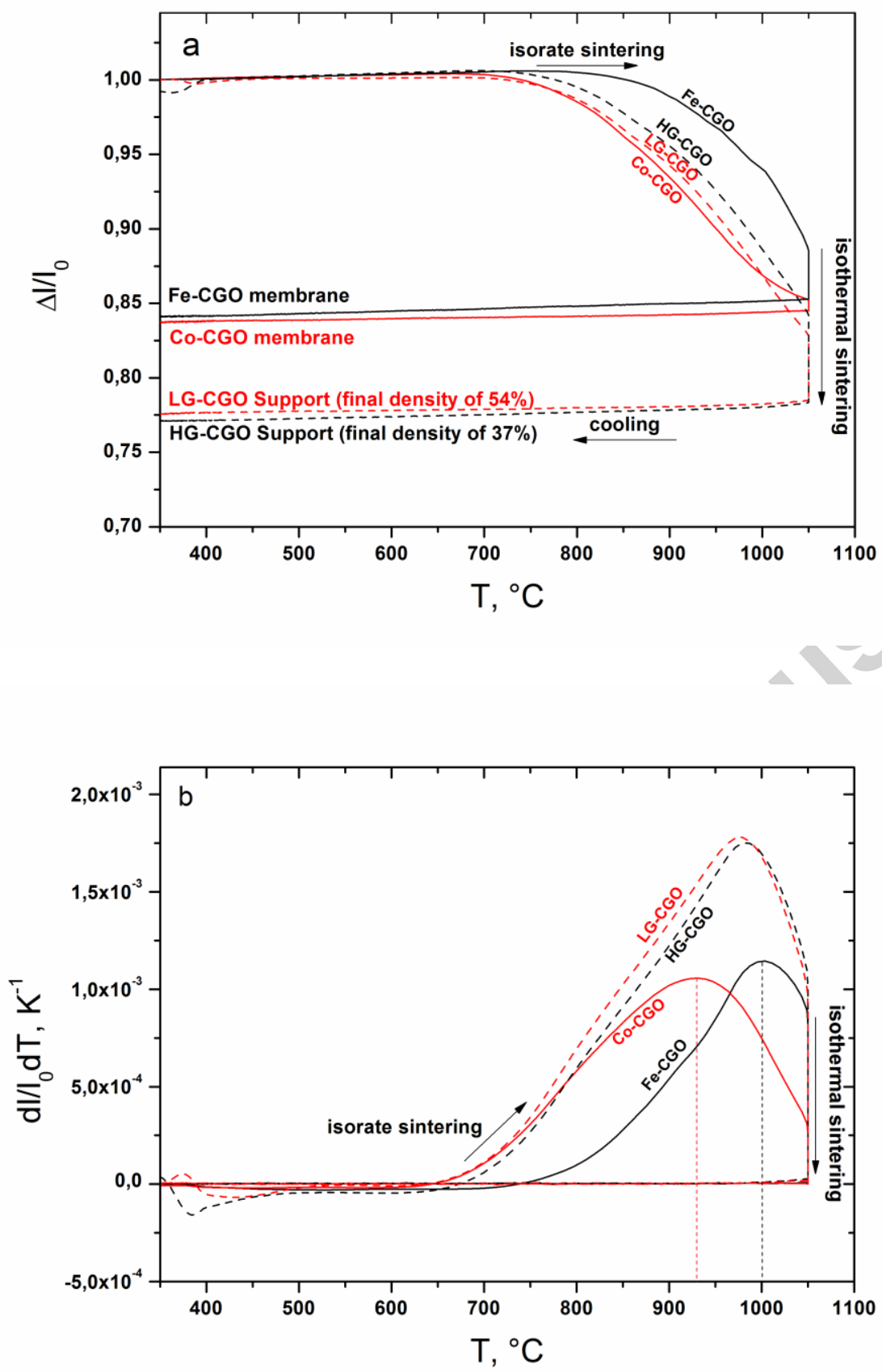

Figure 2: Linear shrinkage (a) and linear shrinkage rates (b) of LG-type CGO support (dotted line), HG-type CGO support (dotted black line), $\mathrm{CGO}$ membrane with $\mathrm{Co}_{3} \mathrm{O}_{4}$ addition (Co-CGO support, continuous line) and $\mathrm{CGO}$ membrane with $\mathrm{Fe}_{2} \mathrm{O}_{3}$ addition (Fe-CGO support, continuous black line). 
In Fig. 2, the final densities of the porous supports, LG-CGO and HG-CGO are marked on the cooling part of the shrinkage curves (the curves with dotted lines) after the isorate sintering (heating) and subsequent isothermal sintering at $1050{ }^{\circ} \mathrm{C}$.. Densities of $38 \%$ and $54 \%$ were achieved for the porous support layers of HG-CGO and LG-CGO, respectively. Furthermore, both CGO membrane layers (Co-CGO and Fe-CGO) have been fully densified reaching final densities of more than $97 \%$. Figure 2 reveals that the difference in shrinkage behaviour of the two different CGO tapes is minor, considering the different graphite content and final densities in the supports (LG-CGO versus HG-CGO). The major difference in sintering activity can be found in the two different CGO membrane tapes that contain different sintering additives of $\mathrm{Fe}_{2} \mathrm{O}_{3}$ (in $\mathrm{Fe}-\mathrm{CGO}$ membrane) and $\mathrm{Co}_{3} \mathrm{O}_{4}$ (in Co-CGO membrane). $\mathrm{Fe}_{2} \mathrm{O}_{3}$ shifts the maximum of the shrinkage rate curve by $72 \mathrm{~K}$ to higher temperatures (from $931{ }^{\circ} \mathrm{C}$ for $\mathrm{Co}_{3} \mathrm{O}_{4}$ to $1003{ }^{\circ} \mathrm{C}$ for $\mathrm{Fe}_{2} \mathrm{O}_{3}$ ). During co-sintering of the porous/dense bi-layer (both CGO layers with $\mathrm{Co}_{3} \mathrm{O}_{4}$ ), the membrane layer reaches its maximum in sintering activity at a temperature of $48{ }^{\circ} \mathrm{C}$ lower than the HG type support layer with the peak of linear shrinkage rate at $979{ }^{\circ} \mathrm{C}$. Additionally, the shrinkage rate curve for the Co-CGO membrane layer is already very low at $1050{ }^{\circ} \mathrm{C}$ (and is further declining towards zero when extrapolating the shrinkage rate curve in Fig. $2 b$ for temperatures of 1100 or $1150{ }^{\circ} \mathrm{C}$ ). Therefore increased camber of the bi-layer structure CGO support/Co-CGO membrane towards the support layer can be expected at a sintering temperature above $1050{ }^{\circ} \mathrm{C}$, due to remaining high sintering activity in the porous layer as described in previous studies [20]. Bi-layers with Co-CGO membrane layer therefore showed in fact significant camber after isothermal treatment at higher temperatures of $1100{ }^{\circ} \mathrm{C}$ and above. As conclusion, such bi-layers (containing $\mathrm{Co}_{3} \mathrm{O}_{4}$ in the membrane) should not be sintered above 
$1100{ }^{\circ} \mathrm{C}$ to avoid extensive camber or even damage of the bi-layer during co-firing. Adding $\mathrm{Fe}_{2} \mathrm{O}_{3}$ to the membrane layer shifts the maximum peak of the membrane layer sintering to 1003 ${ }^{\circ} \mathrm{C}$, which is $34{ }^{\circ} \mathrm{C}$ higher than that of the HG-support. This means that the CGO support now shrinks before the membrane layer and thereby sets the membrane layer under contraction (at low temperatures) which aids densification of the thin CGO membrane layer. Furthermore, the Fe-CGO membrane layer still has similar (high) sintering activity between $1100{ }^{\circ} \mathrm{C}$ and $1200{ }^{\circ} \mathrm{C}$ as the CGO support and thereby reduces the camber formation in direction of the support. The use of $\mathrm{Fe}_{2} \mathrm{O}_{3}$ as sintering aid in the membrane layer can preferably be used to apply sintering temperatures of $1100{ }^{\circ} \mathrm{C}$ (and above) to reduce camber in Fe-CGO asymmetric membranes compared to Co-CGO membranes. Figure 3 shows the cross section of an asymmetric CGO membrane, composed of a high graphite support (HG-CGO) and a CGO membrane layer with $\mathrm{Fe}_{2} \mathrm{O}_{3}$ as sintering aid.

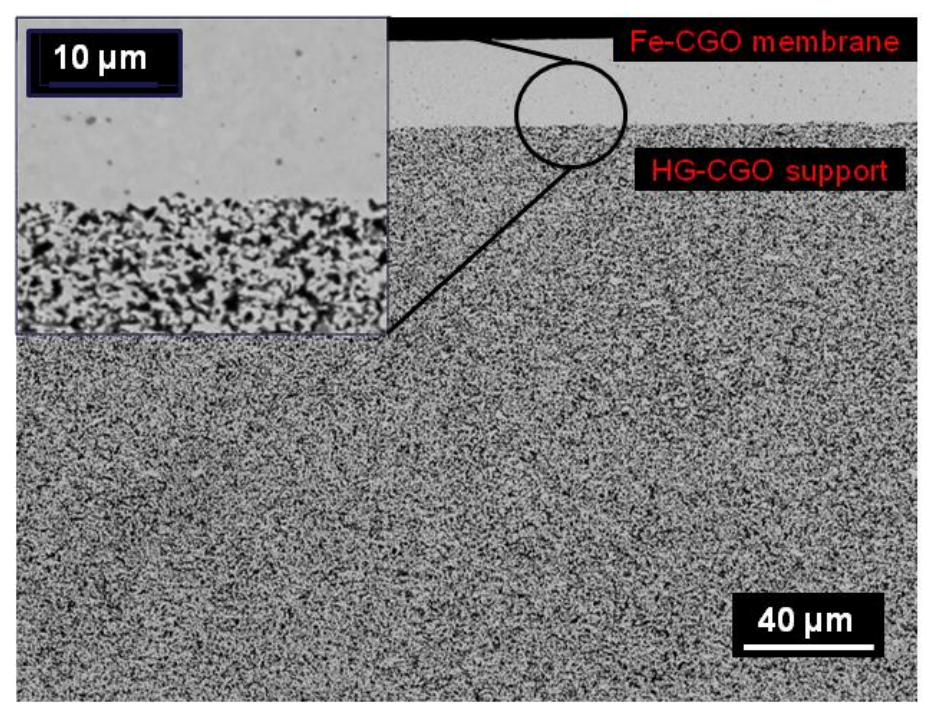


Figure 3: SEM cross-section of an asymmetric bi-layer for an oxygen transport membrane (OTM). Prepared from an HG-CGO support and a Fe-CGO membrane by lamination and isothermal co-sintering at $1150{ }^{\circ} \mathrm{C}$ for $4 \mathrm{hrs}$.

\subsection{Microstructure and gas permeability in the CGO supports}

Starting from the knowledge on the densification behaviour of the two different CGO support tapes with different volume fraction of graphite pore former (LG-CGO and HG-CGO), the microstructure, gas permeability and mechanical behaviour of each single porous support structure was investigated (optimized) as a function of sintering temperature. Linear shrinkage, porosities and densities of LG-CGO and HG-CGO supports are summarized in Table 2 for different isothermal sintering cycles.

Table 2: Linear shrinkages, porosities and densities of low graphite and high graphite supports, LG-CGO and HG-CGO respectively, after 4 hrs sintering treatment at the specified temperature (heating rate $=3 \mathrm{~K} / \mathrm{min}$ ). The 4 digit number in column 1 refers to the isothermal sintering temperature.

\begin{tabular}{|l|c|c|c|c|c|c|}
\hline $\begin{array}{l}\text { Sample } \\
\text { Name }\end{array}$ & $\begin{array}{l}\text { Linear } \\
\text { Shrinkage }\end{array}$ & $\begin{array}{c}{ }^{\mathrm{a}} \text { Total } \\
\text { Porosity }\end{array}$ & $\begin{array}{l}{ }^{\mathrm{b}} \text { Open } \\
\text { Porosity }\end{array}$ & $\begin{array}{l}{ }^{\mathrm{C}} \text { Porosity } \\
\text { Archimedes }\end{array}$ & $\begin{array}{l}{ }^{\mathrm{d}} \text { Apparent } \\
\text { Density }\end{array}$ & $\begin{array}{l}{ }^{\mathrm{e}} \text { Geom. } \\
\text { Density }\end{array}$ \\
\hline LG1050 & 20 & 45.2 & 45.6 & n.m. & n.m. & 3.96 \\
\hline LG1100 & 24.4 & 34.4 & 32.8 & 35.8 & 4.65 & 4.76 \\
\hline LG1150 & 27 & 27.2 & 23.3 & 26.0 & 5.37 & 5.25 \\
\hline LG1200 & 28.8 & 21.2 & 17.8 & 23.12 & 5.57 & 5.72 \\
\hline LG1250 & 29.1 & 11.5 & 11.5 & n.m. & n.m. & 6.41 \\
\hline HG1050 & 20.6 & 63.3 & 62.5 & 64.8 & 2.55 & 2.66 \\
\hline HG1100 & 25.6 & n.m. & 51.1 & n.m. & n.m. & 4.0 \\
\hline
\end{tabular}




\begin{tabular}{|c|c|c|c|c|c|c|}
\hline HG1150 & 29.8 & 44.5 & 44.9 & 45.02 & 3.99 & 4.02 \\
\hline HG1200 & 32.9 & 35.7 & 34.1 & 36.28 & 4.62 & 4.66 \\
\hline HG1250 & 35.7 & 31.6 & 28 & 28.8 & 5.16 & 4.96 \\
\hline
\end{tabular}

${ }^{a}$ The total porosity was calculated from measurement of the geometrical density of sintered discs and theoretical density of CGO. Closed porosity could not be detected by He-pycnometry.

${ }^{\mathrm{b}}$ The open porosity was measured by $\mathrm{Hg}$ porosimetry.

${ }^{c}$ The porosity was measured by Archimedes principle.

${ }^{\mathrm{d}}$ Apparent density (including only closed pores) was measured by He pycnometry.

${ }^{\mathrm{e}}$ Geometrical density (including open and closed porosity) was determined by measuring the dimensions and the weight of CGO supports.

n.m. $=$ not measured

The open porosity values measured by Hg-porosimetry and the porosity calculated from geometrical density measurements (and He-pycnometry measurements resulting in values close to theoretical density) are in good agreement for all samples. This indicates that a significant amount of closed porosity could not be detected for any support structure (in the investigated sintering regime with temperatures up to $1250{ }^{\circ} \mathrm{C}$ ), even not for the support LG1250 with the lowest porosity values of about $12 \%$. Figure 4 is a plot of porosity vs. sintering temperature and shows a linear correlation between these two parameters for the different CGO supports (LG1050 to LG1250 and HG1050 to HG1250). It is worth noting that a relative increase of pore former concentration by 50 vol.- $\%$ (5 vol.- $\%$ absolute increase) induces a parallel shift of the straight line in Figure 3 towards higher values and thereby increases the porosity at all sintering temperatures by about $20 \%$. 


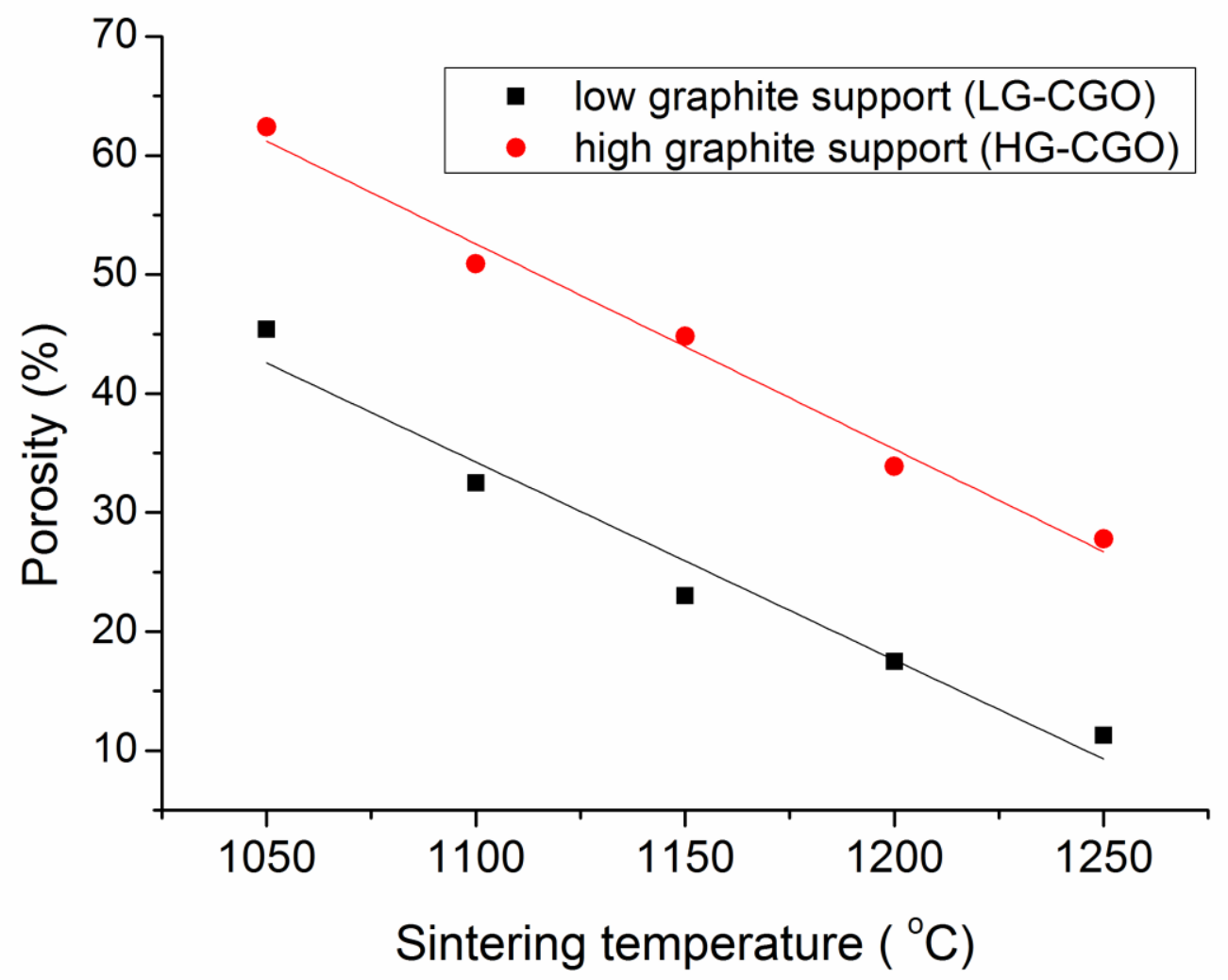

Figure 4: Porosity as a function of sintering temperature for porous CGO supports with low graphite (LG-CGO, filled squares) and high graphite content (HG-CGO, filled circles).

The difference in microstructures of the CGO supports sintered at 3 different temperatures was evaluated by scanning electron microscopy (HRSEM) and can be seen in Figure 5. 

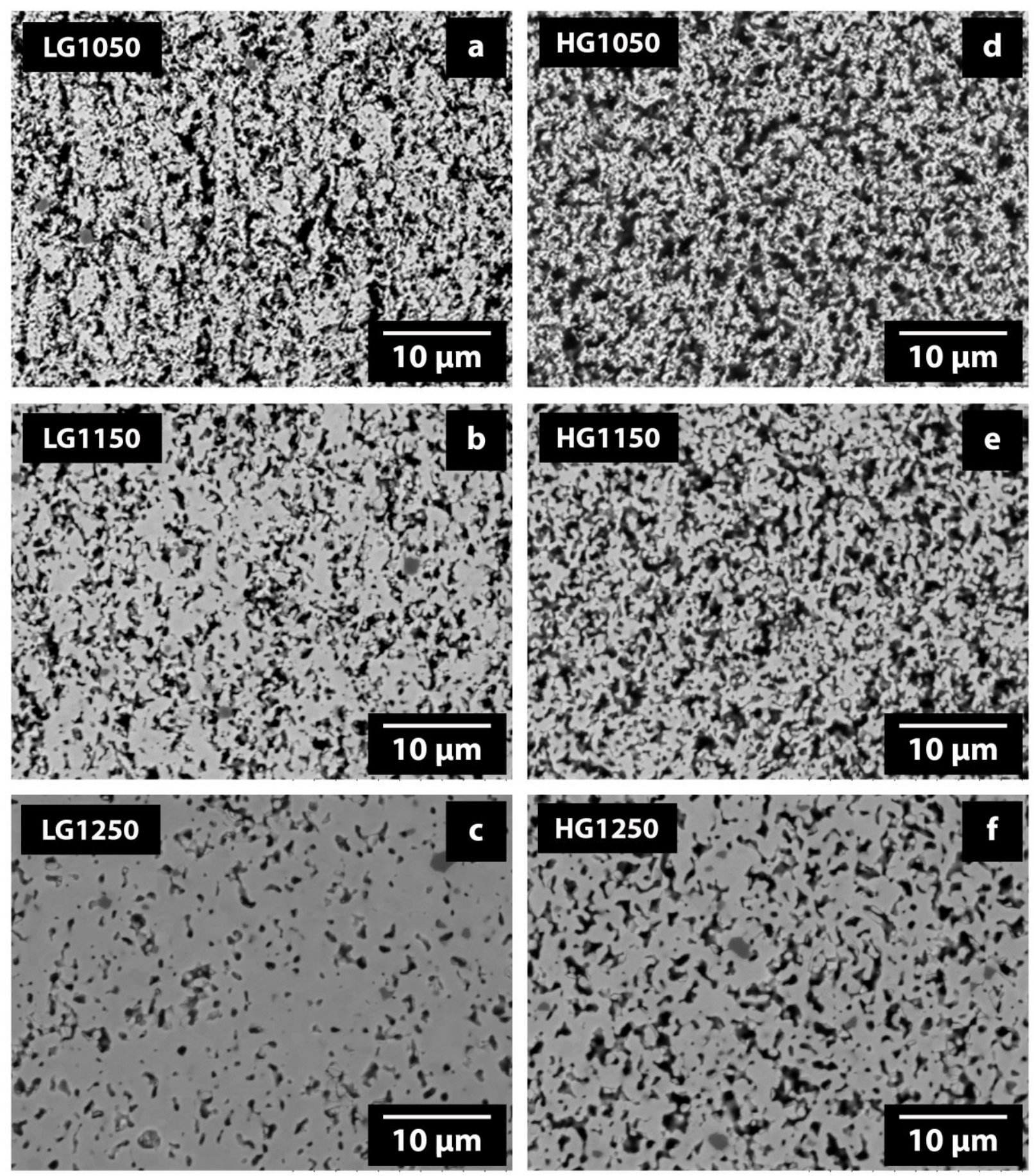

Figure 5: Microstructure of CGO supports by SEM images of polished cross sections of a)

LG1050, b) LG 1150 C) LG1250, d) HG1050, e) HG1150 and f) HG1250. 
In accordance with data reported in Table 2 the porosity of the supports significantly decreases with increasing sintering temperature and porosities are clearly lower for the supports that were prepared with lower graphite concentration (LG-type tapes).

The microstructures of all the porous supports sintered at different temperatures reveal a very homogeneous distribution of porosity without major defects or inhomogeneity along the different tape directions. A significant orientation of the platelet-type graphite pore former in casting direction could not be observed. The two-dimensional picture of the cross-sectional surface suggests that pores are more connected (percolating) in the high graphite support (HG -CGO with 16.5 vol.- $\%$ of graphite) than in the low graphite support (LG-CGO with 11 vol.-\% of graphite). This observation is in agreement with earlier investigations on ceramics using pore former (inclusions), which report the formation of three-dimensional percolating pore network (of the inclusion itself) if the inclusion volume fraction exceeds 16 vol.- \% [17].

\subsection{Gas Permeability in porous CGO supports}

A very important property for the technical application of porous membrane supports in OTM applications is the ability to transport gases through the porous structure in order to supply reactants and remove products from the reaction zone. Figure 6 shows the measured gas permeability for the 2 types of CGO supports, sintered at different temperatures. Inserted in the graph are two representative micrographs of the LG and the HG samples with an almost identical degree of total porosity. 


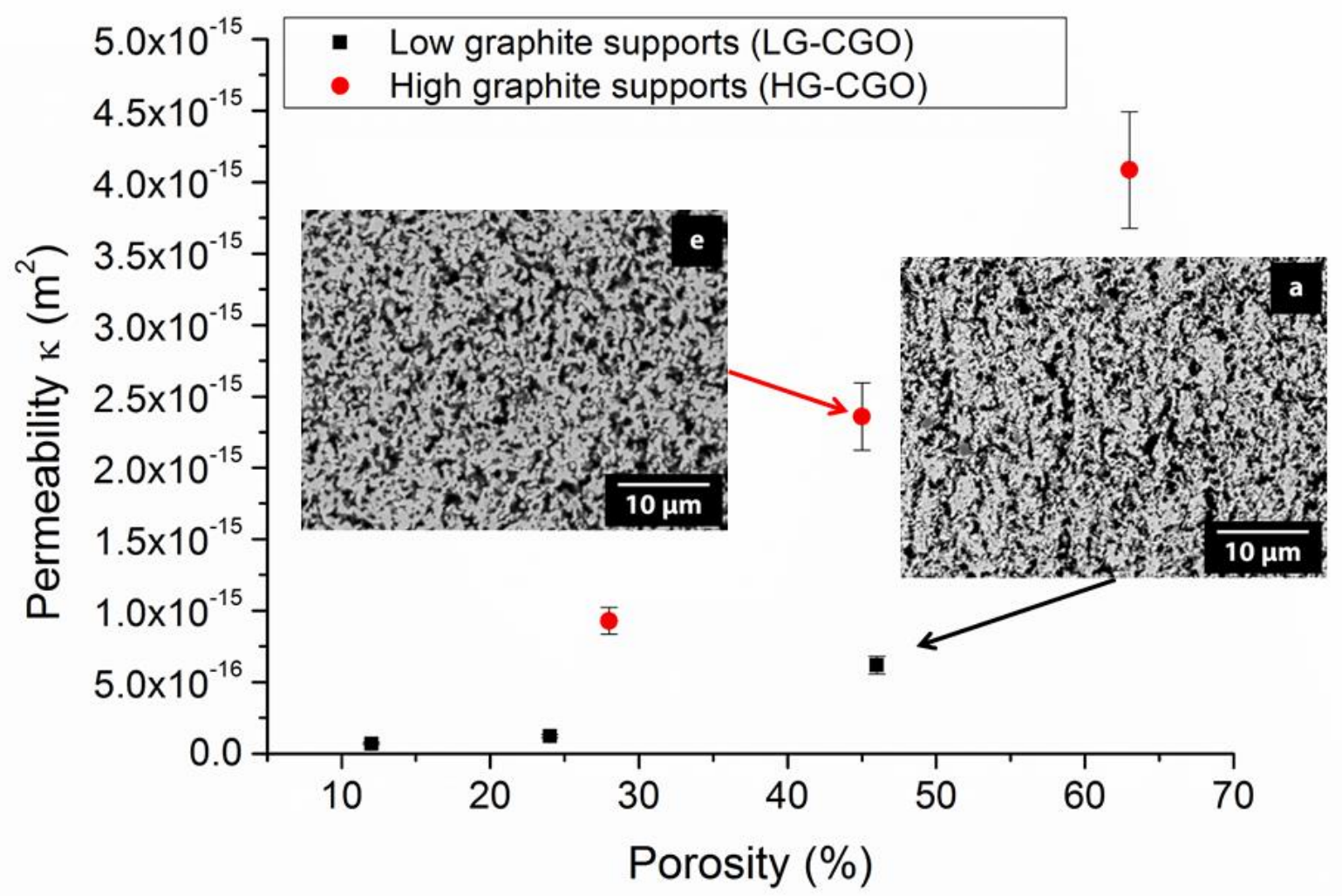

Figure 6: Permeability of CGO supports with low graphite content (LG-CGO, black squares) and with high graphite content (HG-CGO supports, red circles). The microstructures for the low graphite support (LG1050) and the high graphite support (HG1150) with similar total porosity but different permeability are inserted for illustration.

The measured gas permeability in Figure 6 is significantly higher for the HG-CGO supports compared to the supports with low graphite content (LG-CGO), with a factor of 5 higher gas permeability for HG1150 compared to LG1050 at comparable porosities of about $45 \%$. 


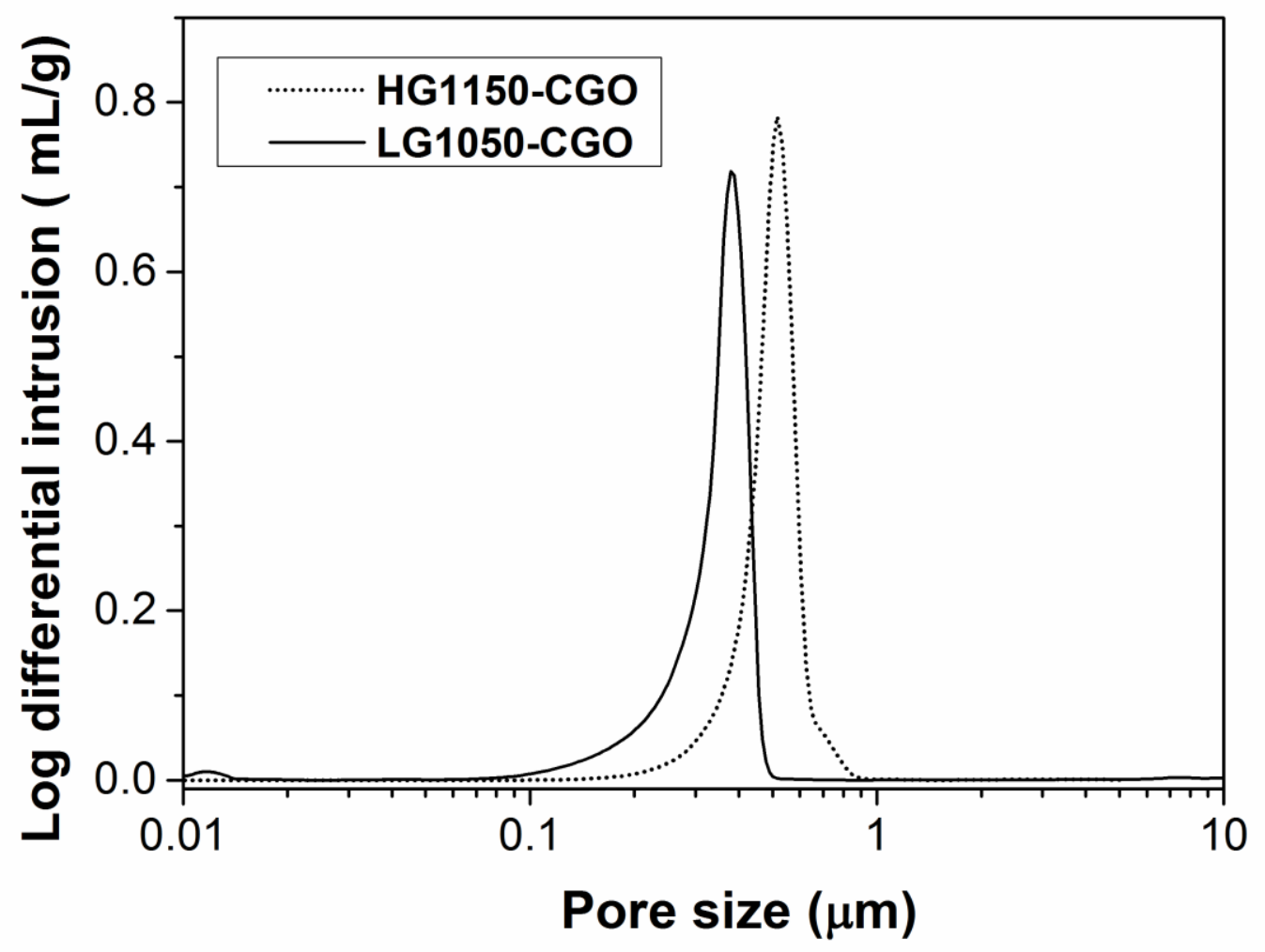

Figure 7: Pore size distribution of CGO supports with comparable total open porosity, measured by Hg-porosimetry: a) low graphite-type support, sintered at $1050{ }^{\circ} \mathrm{C}$ (LG1050) with $45.6 \%$ porosity and b) high graphite-type support, sintered at $1150{ }^{\circ} \mathrm{C}$ (HG1150) with $44.9 \%$ porosity

The gas permeability data and the observed difference in microstructure (both shown in Fig. 6) clearly indicate that a more open, three-dimensional pore network (percolating pore structure) with larger pore channels has been created in the HG-1150 support compared to the LG-1050, despite the fact that latter support is sintered at $100{ }^{\circ} \mathrm{C}$ lower temperature. $\mathrm{Hg}$-porosimetry measurements shown in Fig. 7 confirm a significant enlargement of pore size (at maximum peak size) from $0.38 \mu \mathrm{m}$ to $0.52 \mu \mathrm{m}$. 
The general specification for a unique permeability value for a porous CGO support structure that would be required for the use in OTMs is not trivial. The required permeability of a support depends on the specific commercial membrane application and therefore on several factors, such as the reaction and product gases (under consideration), the oxygen flux that can be achieved by the dense membrane layer (which depends on thickness of the membrane and the driving forces, e.g. pressures and atmospheres). Some general guidelines can however be provided.

For pure oxygen production, using thin film ceria based composite or perovskite membranes, the porous CGO support is preferably placed at the permeate side where low vacuum of approx. 0.2 atm is applied while supplying pressurised air of approx. 5 atm to the feed side (see Figure 8a). An acceptable pressure drop of pure oxygen over the support, providing the driving force for the oxygen flux, would be in the range of $0.05-0.2$ atm. The limiting oxygen flux through the support is plotted as a function of permeability for pressure drops of $0.05,0.1$ and 0.2 atm in Figure $8 \mathrm{a}$, using the viscosity of oxygen at $850{ }^{\circ} \mathrm{C}\left(5.29 \times 10^{-5} \mathrm{~Pa} \mathrm{~s}\right)$ and a support thickness of

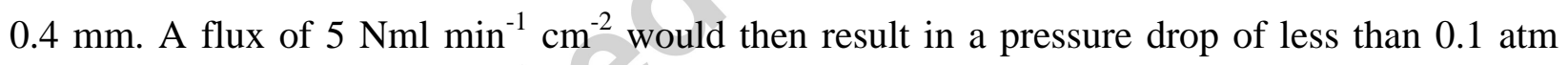
across a $0.4 \mathrm{~mm}$ thick HG1150 support. On the other hand, even a pressure drop of 0.2 atm

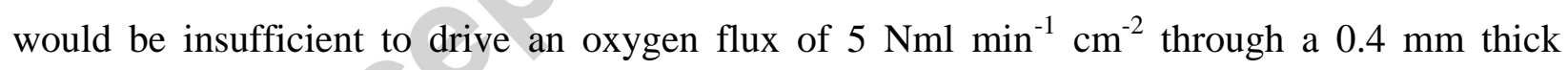
LG1050 support.

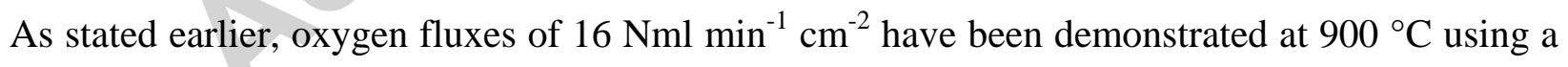
thin film CGO membrane in a syngas application in a previous study [5]. A porous CGO support would preferably be used on the feed side of the membrane in this case to avoid chemical expansion of the CGO under the extremely reducing syngas atmosphere. For this case the membrane arrangement is illustrated in Figure 8b (Case II: Syngas Reaction). As there is no pressure gradient across the CGO support in this case, the oxygen flux is driven by diffusion. 
The dusty gas model [28] has been employed to assess the established $p_{O_{2}}^{\text {int }}$ at the membrane/porous CGO support interface for a given oxygen flux through a $0.4 \mathrm{~mm}$ thick LG1050 or HG1150 support and through a $0.2 \mathrm{~mm}$ thick HG1150 support at $900{ }^{\circ} \mathrm{C}$. Only in the

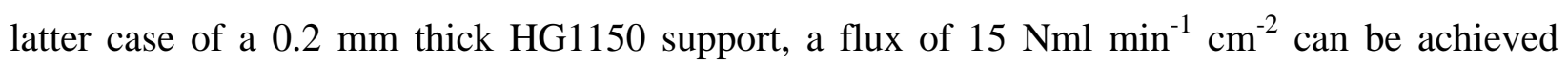
without establishing a prohibitively low $p_{\mathrm{O}_{2}}^{\text {int }}$ value.

a

Case I: Oxygen Separation

Feed: pressurized air $\quad 5 \mathrm{~atm}$

\begin{tabular}{|c|}
\hline Air catalyst \\
\hline Membrane \\
\hline Porous CGo support \\
\hline
\end{tabular}

Permeate: Low vacuum $\mathrm{O}_{2} \quad 0.2 \mathrm{~atm}$

b

\section{Case II: Syngas Reaction}

Feed: atmospheric air $\quad 0.21 \mathrm{~atm}$

\begin{tabular}{|c|}
\hline Porous CGo support \\
\hline Membrane \\
\hline Syngas catalyst \\
\hline
\end{tabular}

Permeate: syngas
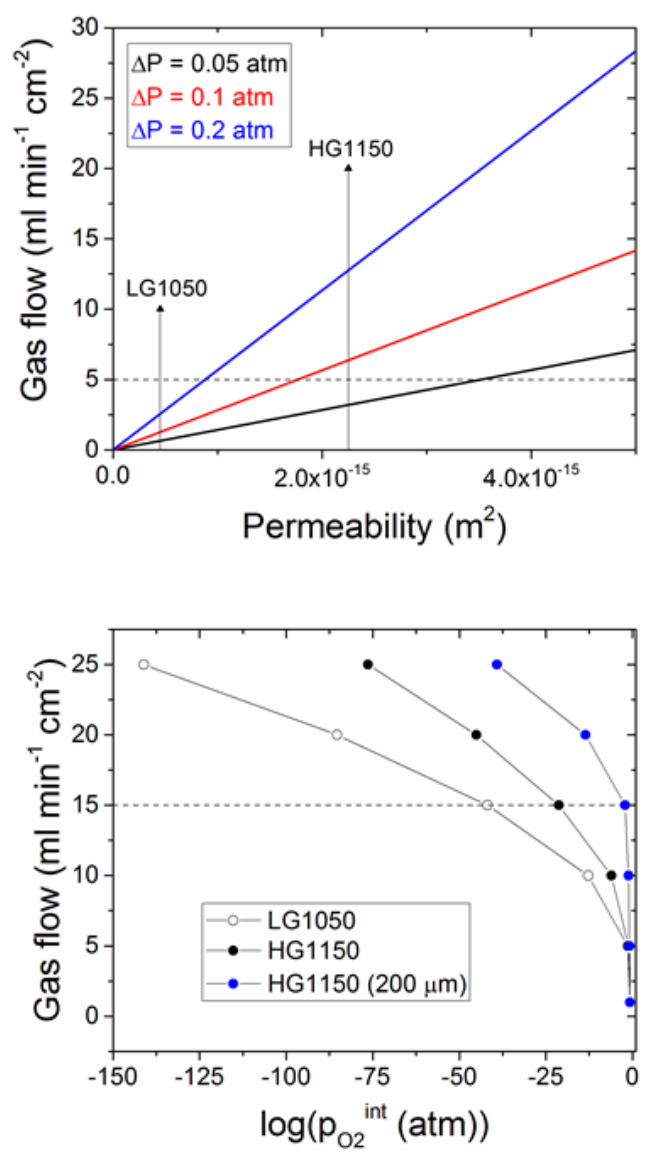

Figure 8: Expected limiting oxygen flux through a porous CGO membrane support (thickness of $0.4 \mathrm{~mm}$ ) for a) oxygen separation (Case I) depending on support permeability at different pressure drops (permeate side) and for b) syngas production (Case II) depending on the $p_{\mathrm{O}_{2}}^{\text {int }}$ at the membrane/porous CGO support interface (feed side). 
To summarise, the CGO supports with the low graphite content clearly fall below a permeability value of $1 \times 10^{-15} \mathrm{~m}^{2}$ and a porosity which is too low for any of the membrane applications discussed above, especially because the permeability might be further (slightly) reduced by impregnation of the required electro catalysts in the porous CGO support after co-firing. Assuming a support thickness of $400 \mu \mathrm{m}$, the supports with high graphite content sintered at $1150^{\circ} \mathrm{C}$ will be suitable for pure oxygen production but not for syngas production. The thickness of the support must be decreased to approx. $200 \mu \mathrm{m}$ for the syngas application to allow reaching the set flux target. In syngas operation, the performance of asymmetric membranes can

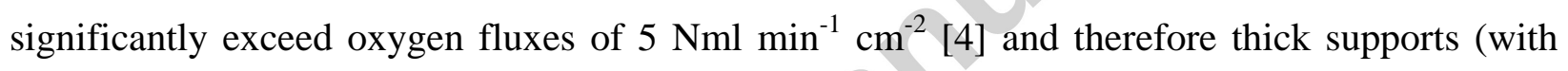
microstructures as discussed in this article) would restrict the membrane performance by gas transport limitation.".

\subsection{Mechanical properties of CGO supports}

The results presented in section 3.3 are in line with expectations, showing that the gas permeability increases with increasing support porosity. Hence, to maximize the transport capabilities of the components the porosity in the support structure should be increased. However, requirements on component reliability both under handling and subsequent use pose conflicting requirements as mechanical strength usually decreases with increasing porosity. Hence, not only the support properties have to be optimized to achieve flat and defect free multilayers but also a microstructure has to be designed that compromises between optimal gas transport properties and mechanical reliability. These conflicting properties were further 
investigated in this work for porous membrane supports. Similar studies have been performed recently for another application of porous CGO structures in electrochemical flue gas purification [24], [29]. The mechanical properties of the different CGO supports were tested for their applicability in OTM reactors by ring-on-ring bending tests with the results listed in Table 3. 25 to 30 specimens were tested in order to obtain reliable assessment of both characteristic strength and the Weibull modulus. An exception is the HG1050 type, where the fracture stresses were too small for an assessment of the actual strength values. A very low strength of maximum $4 \mathrm{MPa}$ was assumed in this case as an upper limit since all samples already broke at a contact load of $2 \mathrm{~N}$. This low mechanical strength could be explained by the very low sintering temperature and thus high porosity of this support type. The overall rather low standard deviation indicates an accurate determination of mechanical properties. It should be noted that an evaluation of the Weibull modulus based on stress and strain data leads to slightly different values since low strength values of specimens are also usually reflected in low Young's moduli. The mechanical properties of the supports shown in Table 3 are comparable to other ceramic membrane candidate materials such as $\mathrm{Ba}_{0.5} \mathrm{Sr}_{0.5} \mathrm{Co}_{0.8} \mathrm{Fe}_{0.2} \mathrm{O}_{3-\delta}$ and $\mathrm{La}_{0.6-\mathrm{x}} \mathrm{Sr}_{0.4} \mathrm{Co}_{0.2} \mathrm{Fe}_{0.8} \mathrm{O}_{3-\delta}(\mathrm{x}=$ $0,0.02)$ [30] or similar porous CGO structures for flue gas purification [29], [31].

Elastic modulus, characteristic fracture strength and rupture strain appear to have a linear dependence on porosity for the considered porosity range, as illustrated in Figure 9.

The fracture strength as well as the elastic modulus decrease with increasing porosity, while the rupture strain increases with increasing porosity suggesting that energy consumption of the porous volume in front of the crack tip enhances the strain value. The strength is crucial in withstanding high pressure differences while the rupture strain might be considered as the critical parameter for the reliability when sealing a component to a material with a different TEC. 


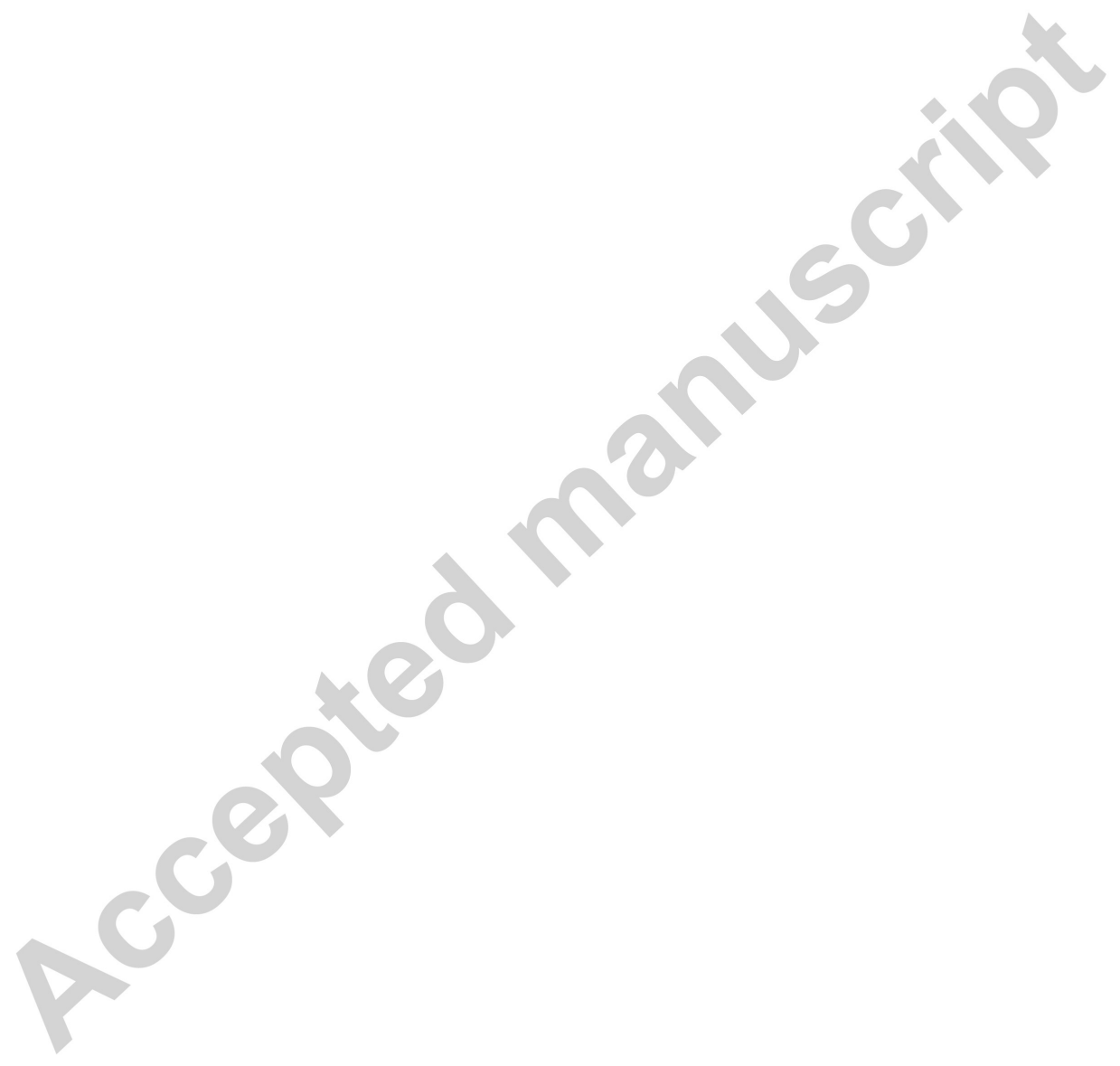


Table 3: Mechanical properties of porous LG-CGO and HG-CGO supports. The Weibull moduli are given in brackets for the characteristic strength and characteristic rupture strain.

\begin{tabular}{ccccc}
\hline & Young's & ${ }^{\mathbf{b}}$ Characteristic & ${ }^{\mathbf{b}}$ Characteristic rupture & \# of \\
Sample ID & modulus $(\mathbf{E})$ & strength $(\boldsymbol{\sigma})$ & strain $(\boldsymbol{\varepsilon})$ & samples \\
& GPa & Mpa & $\%$ & \\
\hline LG1050 & $57 \pm 14$ & $55 \pm 2(5 \pm 1)$ & $0.093 \pm 0.002(10 \pm 2)$ & 28 \\
LG1150 & $118 \pm 15$ & $89 \pm 2(7 \pm 1)$ & $0.075 \pm 0.002(8 \pm 1)$ & 30 \\
LG1250 & $149 \pm 18$ & $92 \pm 3(5 \pm 1)$ & $0.062 \pm 0.002(5 \pm 1)$ & 29 \\
HG1050 & - & $<4$ & & 10 \\
HG1150 & $47 \pm 7$ & $47 \pm 2(6 \pm 1)$ & $0.097 \pm 0.002(8 \pm 2)$ & 25 \\
HG1250 & $97 \pm 21$ & $80 \pm 2(7 \pm 1)$ & $0.079 \pm 0.002(10 \pm 2)$ & 29
\end{tabular}

${ }^{a}$ The fracture strength of HG1050 type was too low for testing. A maximum fracture strength of $4 \mathrm{MPa}$ can be used as an approximation for support HG1050.

${ }^{\mathrm{b}}$ In brackets in columns 3 and 4, the Weibul moduli are added to the characteristic strength and rupture values 
a.

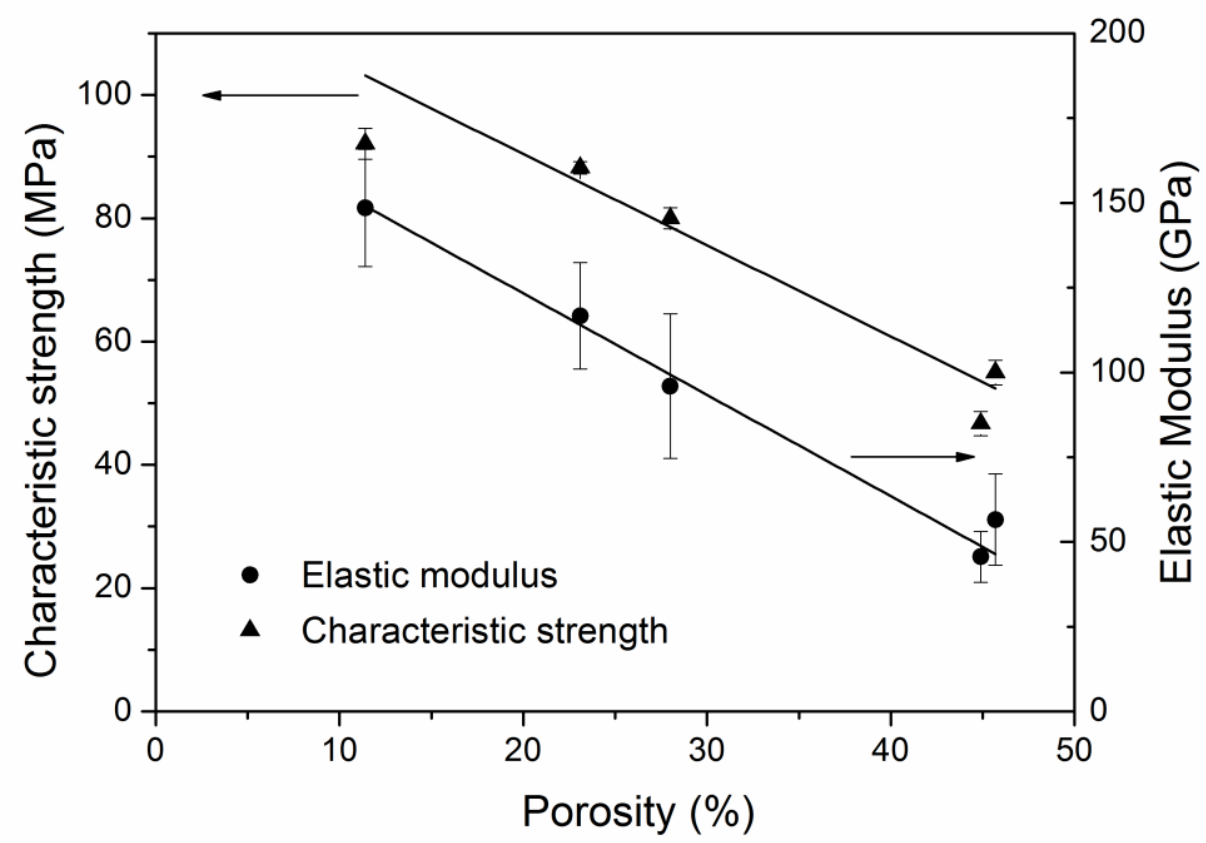

b.

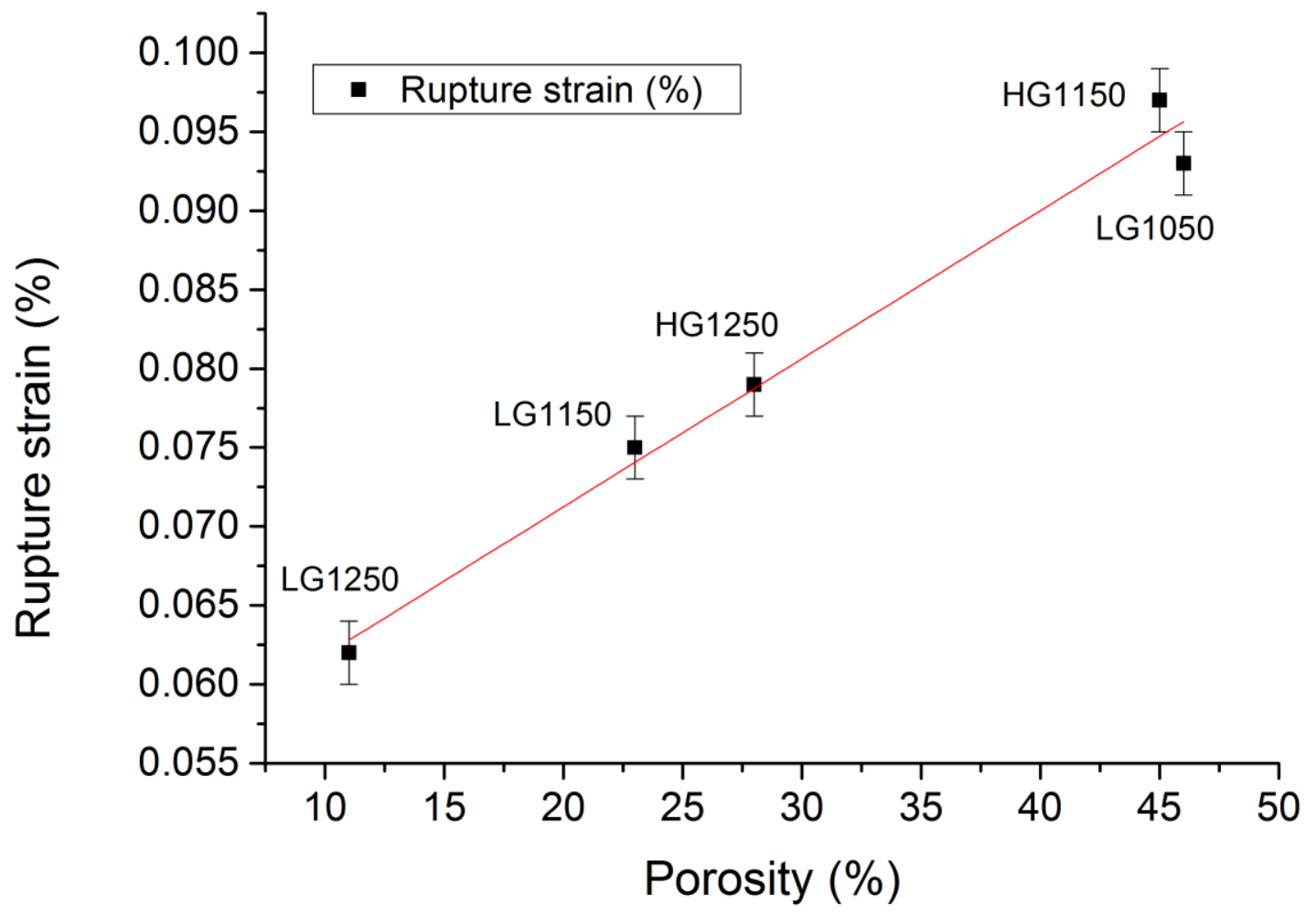


Figure 9: Dependence of mechanical properties of low graphite (LG) and high graphite (HG) CGO supports on porosity: a) characteristic fracture strength and elastic modulus; b) characteristic fracture strain.

Characteristic strength and rupture strain are important for the mechanical reliability of the samples. Ultimately, the quality of the highly porous samples might be considered to be better than the low porosity samples as the measured rupture strain is higher even though there is some reduction in the strength. It is noteworthy that the two different tape recipes fall on the same trend curve. The mechanical properties are primarily determined by the achieved porosity and it does not matter if a specific porosity is achieved by changing the amount of pore former or the firing temperature (within the investigated range of parameters).

\section{Summary and Conclusions}

Porous CGO supports for oxygen transport membranes (OTMs) have been prepared by tape casting with different amount of graphite as pore former and cobalt oxide as sintering additive at a sintering temperature of 1050 to $1250{ }^{\circ} \mathrm{C}$ for the co-sintering with a thin, dense CGO membrane layer. Mechanical strength and Young's-modulus of all supports decrease linearly with porosity as expected. Interestingly, at comparable total porosities, the CGO supports with high graphite content showed significantly higher gas permeability than the low graphite supports. This indicates significantly improved pore connectivity in the CGO supports with high graphite content (passing the percolation limit) compared to low graphite CGO supports (at comparable porosities). As a consequence of this favourable microstructure of the HG-CGO supports, the co-firing temperature with a dense CGO membrane can be increased by $100{ }^{\circ} \mathrm{C}$ 
(from $1050^{\circ} \mathrm{C}$ at $1150^{\circ} \mathrm{C}$ ), resulting in acceptable permeability for gas transport through such CGO supports (with a thickness of $0.4 \mathrm{~mm}$ ) in asymmetric membranes for pure oxygen production. Syngas application would additionally require a reduced support thickness (towards $200 \mu \mathrm{m}$ ) to sustain large fluxes about $\sim 15 \mathrm{ml} \mathrm{min}^{-1} \mathrm{~cm}^{-2}$. Optical dilatometry showed that the sintering activity of the dense CGO membrane layer can be adjusted for a higher co-sintering temperature with a porous support, utilizing $\mathrm{Fe}_{2} \mathrm{O}_{3}$ as sintering aid in the membrane layer, thereby reducing camber formation (which is observed to be significant in co-sintering of asymmetric CGO membranes, using $\mathrm{Co}_{3} \mathrm{O}_{4}$ in both layers). An increased bilayer sintering temperature of $1150{ }^{\circ} \mathrm{C}$ has also benefits in further membrane fabrication steps. For example, a ceramic catalyst layer (such as perovskites as oxygen reduction catalyst) can be applied by screen printing and subsequent sintering at sufficiently high temperatures up to about $1050{ }^{\circ} \mathrm{C}$ without risk of further bi-layer distortion due to further support sintering. With the firing of the HG-supports at $1150{ }^{\circ} \mathrm{C}$ decent mechanical properties were obtained (rupture strain $\sim 0.095 \%$ and characteristic strength $\sim 47 \mathrm{MPa}$ ).

In summary, the microstructure of porous CGO supports (pore structure) has been optimized for implementation in OTMs by varying the amount of graphite pore former. Varying also the firing temperature and the choice of the sintering aid in the support and in the gas tight membrane layer allowed the fabrication of flat asymmetric membrane components that could be tested with respect to oxygen flux.

\section{Acknowledgements}

The research leading to these results has received funding from the European Union's Seventh Framework Programme FP7/2007-2013 under grant agreement n 228701, $\mathrm{n}^{\circ} 268165$ (NASA- 
OTM, HETMOC) and from the Scientific Research Councils on Technology and Production

Sciences (FTP) (Contract No. 09-072888, OPTIMAC), which is part of the Danish Council for Independent Research (DFF). Marianne Nielsen is thankfully acknowledged for Hg-porosimetry measurements. Furthermore, the authors would like to thank Ralf Küppers for the mechanical testing of the materials.

\section{References}

[1] J.C. Smart, S; Lin, C. X. C.; Ding, L; Thambimuthu, K.; Diniz da Costa, Ceramic membranes for gas processing in coal gasification, Energy Environ. Sci. 3 (2010) 253. doi:10.1039/c003390c.

[2] J. Sunarso, S. Baumann, J.M. Serra, W. A. Meulenberg, S. Liu, Y.S. Lin, et al., Mixed ionic-electronic conducting (MIEC) ceramic-based membranes for oxygen separation, J. Memb. Sci. 320 (2008) 13-41. doi:10.1016/j.memsci.2008.03.074.

[3] A. Leo, S. Liu, J.C.D. da Costa, Development of mixed conducting membranes for clean coal energy delivery, Int. J. Greenh. Gas Control. 3 (2009) 357-367. doi:10.1016/j.ijggc.2008.11.003.

[4] A. Kaiser, S. Foghmoes, C. Chatzichristodoulou, M. Søgaard, J. A.Glasscock, H.L.L. Frandsen, et al., Evaluation of thin film ceria membranes for syngas membrane reactorsPreparation, characterization and testing, J. Memb. Sci. 378 (2011) 51-60. doi:10.1016/j.memsci.2010.12.012.

[5] C. Chatzichristodoulou, M. Søgaard, J. A. Glasscock, A. Kaiser, S.P.V. Foghmoes, P.V. Hendriksen, Oxygen Permeation in Thin, Dense $\mathrm{Ce}_{0.9} \mathrm{Gd}_{0.1} \mathrm{O}_{1.95 \text {-delta }}$ Membranes II. Experimental Determination, J. Electrochem. Soc. 158 (2011) F73-F83. doi:10.1149/1.3559189.

[6] M.P. Lobera, J.M. Serra, S.P. Foghmoes, M. Søgaard, A. Kaiser, On the use of supported ceria membranes for oxyfuel process/syngas production, J. Memb. Sci. 385-386 (2011) 154-161. doi:10.1016/j.memsci.2011.09.031.

[7] A. Malekzadeh, M. Abedini, A.A. Khodadadi, M. Amini, H.K. Mishra, A. K. Dalai, Critical influence of $\mathrm{Mn}$ on low-temperature catalytic activity of $\mathrm{Mn} / \mathrm{Na}_{2} \mathrm{WO}_{4} / \mathrm{SiO}_{2}$ catalyst for oxidative coupling of methane, Catal. Letters. 84 (2002) 45-51. doi:10.1023/A:1021020516674.

[8] B.T. Daslet, Measurement and modeling of the defect chemistry and transport properties of ceramic mixed ionic and electronic conductors, Twente University, 2005.

[9] M. Mogensen, Physical, chemical and electrochemical properties of pure and doped ceria, Solid State Ionics. 129 (2000) 63-94. doi:10.1016/S0167-2738(99)00318-5.

[10] A. Samson, M. Sogaard, R. Knibbe, N. Bonanos, High Performance Cathodes for Solid 
Oxide Fuel Cells Prepared by Infiltration of $\mathrm{La}_{0.6} \mathrm{Sr}_{0.4} \mathrm{CoO}_{3-\delta}$ into Gd-Doped Ceria, J. Electrochem. Soc. 158 (2011) B650. doi:10.1149/1.3571249.

[11] M. Pihlatie, A. Kaiser, P.H. Larsen, M. Mogensen, Dimensional Behavior of Ni-YSZ Composites during Redox Cycling, J. Electrochem. Soc. 156 (2009) B322. doi:10.1149/1.3046121.

[12] D. Sarantaridis, a. Atkinson, Redox Cycling of Ni-Based Solid Oxide Fuel Cell Anodes: A Review, Fuel Cells. 7 (2007) 246-258. doi:10.1002/fuce.200600028.

[13] M. Pihlatie, A. Kaiser, M. Mogensen, Redox stability of SOFC: Thermal analysis of NiYSZ composites, Solid State Ionics. 180 (2009) 1100-1112. doi:10.1016/j.ssi.2009.04.011.

[14] M.H. Pihlatie, H.L. Frandsen, A. Kaiser, M. Mogensen, Continuum mechanics simulations of $\mathrm{NiO} / \mathrm{Ni}-\mathrm{YSZ}$ composites during reduction and re-oxidation, J. Power Sources. 195 (2010) 2677-2690. doi:10.1016/j.jpowsour.2009.11.079.

[15] S.F. Corbin, P.S. Apté, Engineered Porosity via Tape Casting, Lamination and the Percolation of Pyrolyzable Particulates, J. Am. Ceram. Soc. 82 (1999) 1693-1701. doi:10.1111/j.1151-2916.1999.tb01988.x.

[16] A.L. Shaula, E.N. Naumovich, A.P. Viskup, V. V. Pankov, A. V. Kovalevsky, V. V. Kharton, Oxygen transport in $\mathrm{La}_{2} \mathrm{NiO}_{4+\delta}$ : Assessment of surface limitations and multilayer membrane architectures, Solid State Ionics. 180 (2009) 812-816. doi:10.1016/j.ssi.2009.01.005.

[17] F. Zok, F.F. Lunge, J.I. Porter, Packing Density, (1991) 1880-1885.

[18] D.W. Ni, V. Esposito, C.G. Schmidt, T.T. Molla, K.B. Andersen, A. Kaiser, et al., Camber evolution and stress development of porous ceramic bilayers during co-firing, J. Am. Ceram. Soc. 96 (2013) 972-978. doi:10.1111/jace.12113.

[19] M. Lo Faro, D. La Rosa, G. Monforte, V. Antonucci, A. S. Arico, P. Antonucci, Propane conversion over a Ru/CGO catalyst and its application in intermediate temperature solid oxide fuel cells, J. Appl. Electrochem. 37 (2006) 203-208. doi:10.1007/s10800-006-92455.

[20] A. Kaiser, A. S. Prasad, S.P. Foghmoes, S. Ramousse, N. Bonanos, V. Esposito, Sintering process optimization for multi-layer CGO membranes by in situ techniques, J. Eur. Ceram. Soc. 33 (2013) 549-556. doi:10.1016/j.jeurceramsoc.2012.09.021.

[21] C. Kleinlogel, L.J. Gauckler, Sintering and properties of nanosized ceria solid solutions, Solid State Ionics. 135 (2000) 567-573. doi:10.1016/S0167-2738(00)00437-9.

[22] E. Olevsky, T.T. Molla, H.L. Frandsen, R. Bjørk, V. Esposito, D.W. Ni, et al., Sintering of multilayered porous structures: Part I-constitutive models, J. Am. Ceram. Soc. 96 (2013) 2657-2665. doi:10.1111/jace.12375.

[23] E. Raether, R. Hofmann, G. Muller, H.J. Solter, A novel thermo-optical measuring system for the in situ study of sintering processes, J. Therm. Anal. Calorim. 53 (1998) 717-735. doi:10.1023/A:1010111023658.

[24] C.G. Schmidt, K.B. Andersen, Z. Fu, K.K. Hansen, A. Roosen, A. Kaiser, Effect of Pore Formers on Properties of Tape Cast Porous Sheets for Electrochemical Flue Gas 
Purification, J. Eur. Ceram. Soc. (2015) 1-9. doi:10.1016/j.jeurceramsoc.2015.09.030.

[25] F. Raether, R. Springer, S. Beyer, Optical dilatometry for the control of microstructure development during sintering, Mater. Res. Innov. 4 (2001) 245-250. doi:10.1007/s100190000101.

[26] G. Pe, T. Bause, J. Malzbender, Ring-on-ring testing of thin , curved bi-layered materials, 31 (2011) 2037-2042. doi:10.1016/j.jeurceramsoc.2011.05.021.

[27] W. Schmitt, K. Blank, G. Schönbrunn, Experimentelle Spannungsanalyse zum Doppelringverfahren, Sprechsaal. 116 (1983) 397-405.

[28] C. Chatzichristodoulou, M. Søgaard, P. V Hendriksen, Oxygen permeation in thin, dense $\mathrm{Ce}_{0.9} \mathrm{Gd}_{0.1} \mathrm{O}_{1.95-\delta}$ membranes I. Model study, J. Electrochem. Soc. 158 (2011) F61-F72. doi:10.1149/1.3556096.

[29] B. Charlas, C.G. Schmidt, H.L. Frandsen, K.B. Andersen, D. Bocaccini, K.K. Hansen, et al., Influence of Pore Former on Porosity and Mechanical Properties of Tape-Cast $\mathrm{Ce}_{0.9} \mathrm{Gd}_{0.1} \mathrm{O}_{1.95}$ Electrolytes for Electrochemical Flue Gas Purification, J. Am. Ceram. Soc. (2015). doi:10.1016/j.ceramint.2015.11.147.

[30] G. Pećanac, S. Foghmoes, M. Lipińska-Chwałek, S. Baumann, T. Beck, J. Malzbender, Strength degradation and failure limits of dense and porous ceramic membrane materials, J. Eur. Ceram. Soc. 33 (2013) 2689-2698. doi:10.1016/j.jeurceramsoc.2013.04.018.

[31] G. Pećanac, S. Baumann, J. Malzbender, Mechanical properties and lifetime predictions for $\mathrm{Ba}_{0.5} \mathrm{Sr}_{0.5} \mathrm{Co}_{0.8} \mathrm{Fe}_{0.2} \mathrm{O}_{3-\delta}$ membrane material, J. Memb. Sci. 385-386 (2011) 263-268. doi:10.1016/j.memsci.2011.10.005. 


\section{Highlights}

- Design of porous ceria supports for asymmetric oxygen transport membranes

- Investigation of support microstructure, mechanical properties and gas permeability

- Pore former percolation at constant porosity increases gas permeability significantly

- Dusty gas model predicts gas transport limitations through supports at high fluxes

- Use of sintering aids to co-sinter defect-free multilayers of support and membrane 